2010-01

\title{
What does doodling do?
}

\author{
Andrade, Jackie
}

http://hdl.handle.net/10026.1/4701

10.1002/acp. 1561

Applied Cognitive Psychology

Wiley

All content in PEARL is protected by copyright law. Author manuscripts are made available in accordance with publisher policies. Please cite only the published version using the details provided on the item record or document. In the absence of an open licence (e.g. Creative Commons), permissions for further reuse of content should be sought from the publisher or author. 


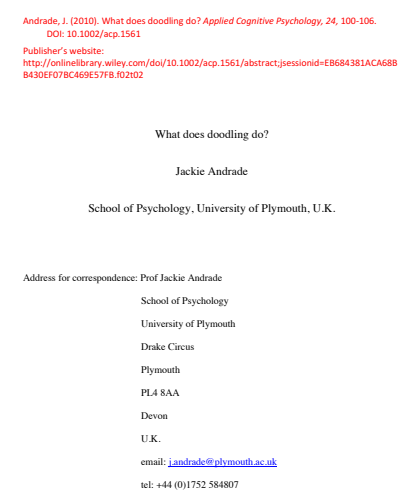




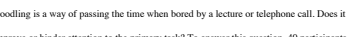

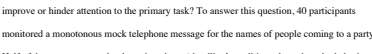

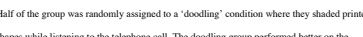

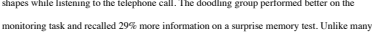

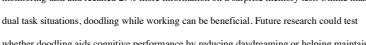

whether dooding aids coge 


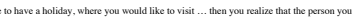

berve

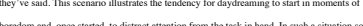

montem.

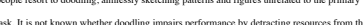

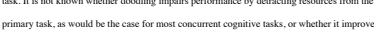

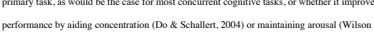

\& Kom, 2007), This question ties into norer general issues in cognitive and appliced

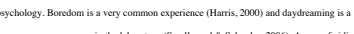

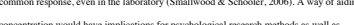

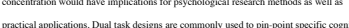

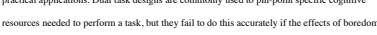

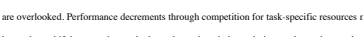

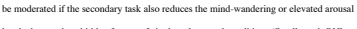

Sevels that can be a hidden featur

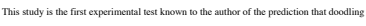

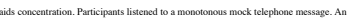

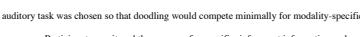

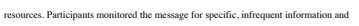




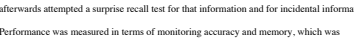

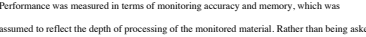

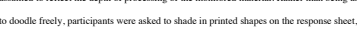

without woryying about the speed and neaterss of their shading. The hope was that

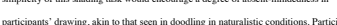

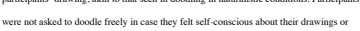

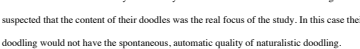

Methax

Participants and design

Participants were 40 members of the MRC A Applied Pyychology Unit (row he Coginition and

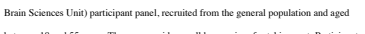

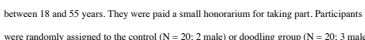

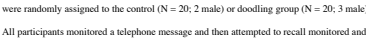

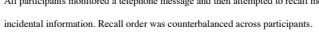

Materials

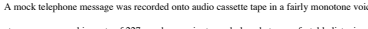

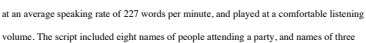




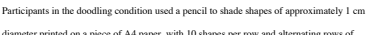

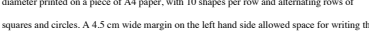
rget information. Control participansts wrote he target information on a lined piece of paper. Procedure

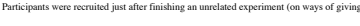

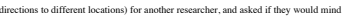

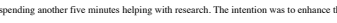

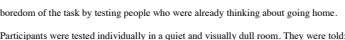

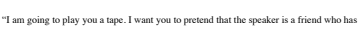

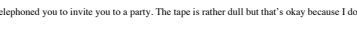
mone comene.D Do not witite anylhing elex:

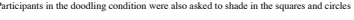

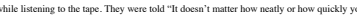

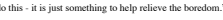

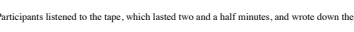

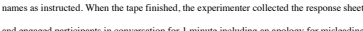




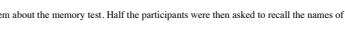

me

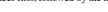

Results

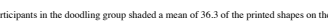

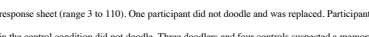
whe comitot

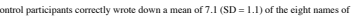

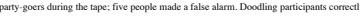

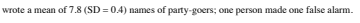

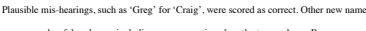

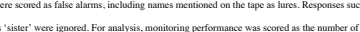

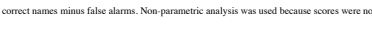

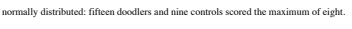

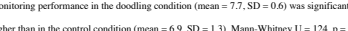
one-tailed.

Recall performance was soored separately fy for names and places, wing the definitions of

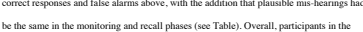




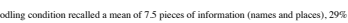

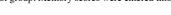

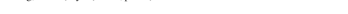

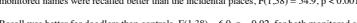

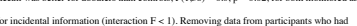
(1)

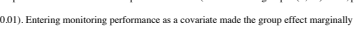
$137=38 . p=0.058$.

Discussion

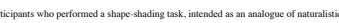

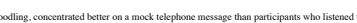

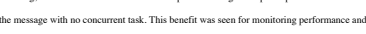

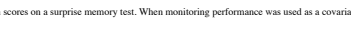

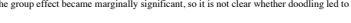

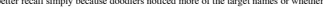

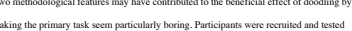

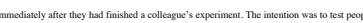
when they were more perene to bordon than if they had just arrived at the laborator. although we have no evidence that this was he case. Evergone was told har the tape would

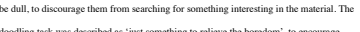


.

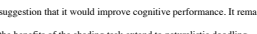
ce benenfis of the the the

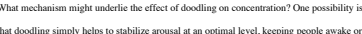

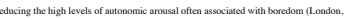

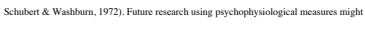

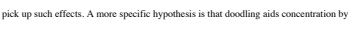

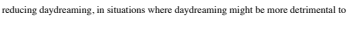

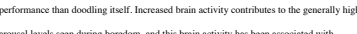

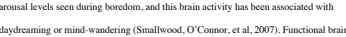

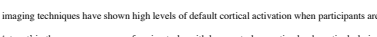

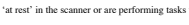

Daydreaming occurs most offen in tasks with few cognitive demanads (e.g. Antrobus, 1968 )

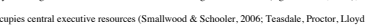

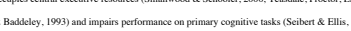

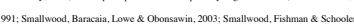
ment

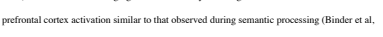

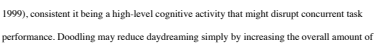

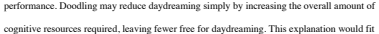




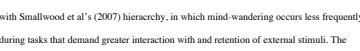

during tasks that demand greater interscition with and reternion of external stimuli. The

of he basic task was low. Because participants were not told about the forthcoming memor

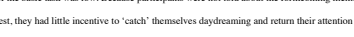

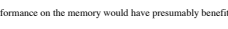

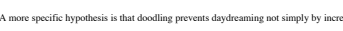

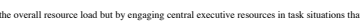

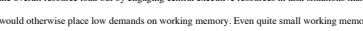

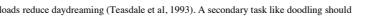

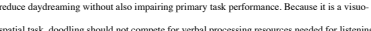

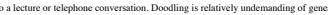

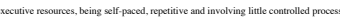

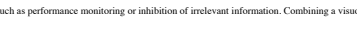

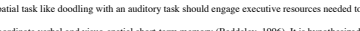

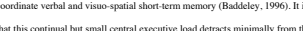
wediory task vere is suffricient

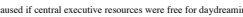

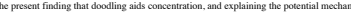

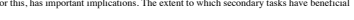




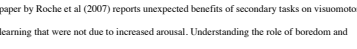

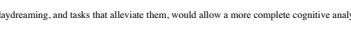

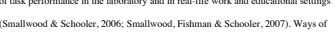

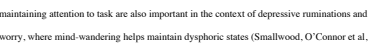

2007. 


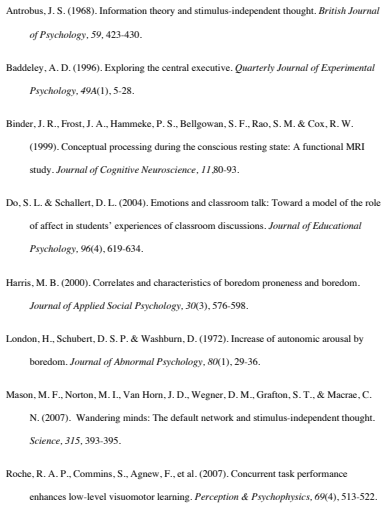


S46-958.

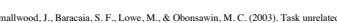

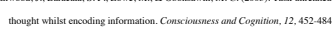

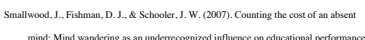

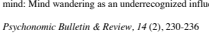

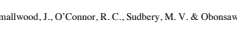

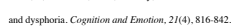

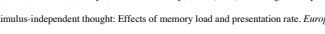

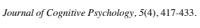

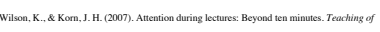

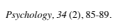




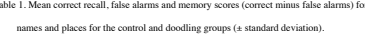

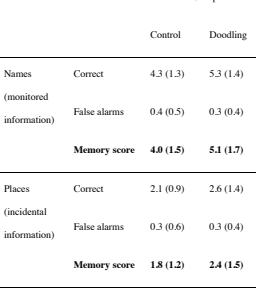




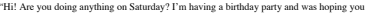

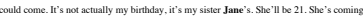

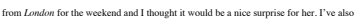

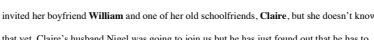

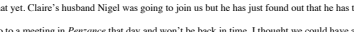

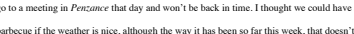

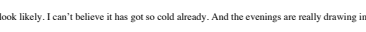

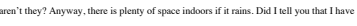

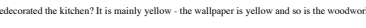

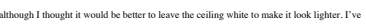

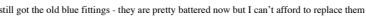

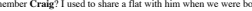
ooking for that bank in Glowerester He has bought a house in Colcheserer now but he

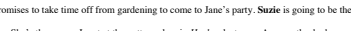

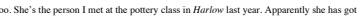
fally good at it and may even be having an exhibition of her work soon. Will you be able

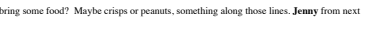

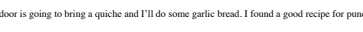

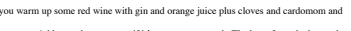




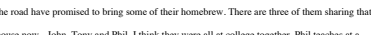

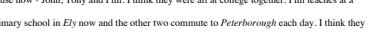

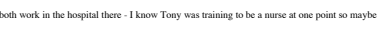

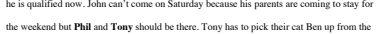

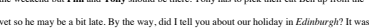
complete disasere. We were camping and it rained constantly. We spent most of the time in

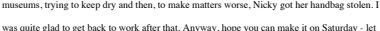

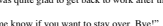

